Proceedings of the Seminar on the Social and Economic Effects of Earthquake Prediction, 12 October, 1977.

\title{
THE EFFECTS OF EARTHQUAKE PREDICTION ON THE MINISTRY OF WORKS AND DEVELOPMENT
}

\author{
A. G. Stirrat*
}

In this short paper on the effects of earthquake prediction on the Ministry of Works and Development it has been decided to consider the answers to some of the questions posed by Haas and Mileti in their paper published in the Bulletin of the N.2. National Society for Earthquake Engineering in December, 1976.

The first matter requiring clarification is the credibility of the prediction process, and the effect of this on the advisory and technical functions of the department. It is assumed for the purposes of this discussion that the state of the art has advanced considerably on what is practised today, and that seismologists would be able to quote specific data on the time, place and magnitude of an earthquake in any seismically active area of the world.

The department would accept such information on the basis that it provides data in support of the design and construction of seismically resistant structures. It would be appreciated that unpredicted earthquakes could still occur, and that while this situation would make no difference to design philosophy and approach, it could have a marked effect on advisory functions.

In the provision of public facilities such as buildings, transportation systems, power supply and other utilities, allowance is already made in their design and construction for two of the three principal elements of earthquake prediction. The N.Z. Standard Code of Practice for the Design of Buildings has detailed provisions for earthquake resistance based, amongst many other factors, on certain earthquake intensities in three distinct seismic zones throughout New Zealand. Thus, the components of place and magnitude are already allowed for within recent well designed structures. The assumption is made that within the lifetime of the structure or facility, it will experience an earthquake of a certain maximum magnitude. From a purely structural point of view, therefore, it can be stated that earthquakes are already predicted in the design of our modern facilities. If prediction progresses to the stage of a short range forecast as far as the time of the event is concerned, this should make little or no difference to the purely technical approach. This would be true particularly if the state of the art does not preclude the possibility of unpredicted earthquakes. In such a case, no real advance has been made to assist the structural engineer.

In fact, unless prediction includes

* Chief Civil Engineer, Ministry of Works and Development. precise information on anticipated ground movements at the time of the earthquake, structurai engineers will have no more information than is currently available and based on past occurrences. The direction of movement and vibration characteristics of the ground on which structures are founded, as related to a particular predicted earthquake would enable a more precise forecast to be given on building performance. Anything less than this would make it difficult for the engineer to take advantage of the forecast.

The department's advisory functions raise the question of information and education of the country's political leaders and the public at large. There can be no doubt that government, together with all other authorities, would have to be appraised of any information which may become available from earthquake prediction. It is not difficult to imagine that the consequences of such information could be quite chaotic before the event. In fact, in many ways they could be more disastrous than the event itself. In spite of this and even if it was possible to keep the information secret, many would find it professionally and morally wrong to withhold knowledge of prediction from the public.

Society's reaction to earthquake prediction could well result in a sharp decline in the availability of capital for new works in the forecast area. At the same time, a large proportion of people would be living and working in unsafe conditions. While such conditions appear to be generally accepted today without prediction, forecasting a damaging earthquake in the near future would probably remove such apathy.

With the distinct possibility that prediction could involve one of New Zealand's large urban areas, the vulnerability of existing facilities would need urgent assessment. At the present time, there is a growing record of the condition of buildings occupied by government departments, but this exercise has not received any particular priority. There would be a need to change the tasks and duties of a significant proportion of the department's staff to prepare inventories, gather information, and analyse the performance of substandard structures in an attempt to reduce the risk of death or injury.

Such an exercise would result in more detailed knowledge of the performance of public buildings and facilities. Recommendations to government would call for urgent and in many cases extreme remedial work not only to minimise danger to people, but also to safeguard the 
performance of utilities, such as transport, power and water supplies.

Earthquake prediction could therefore result in increasing responsibilities and a change of emphasis for the works programme of the Ministry of Works and Development. While the construction of new projects in the forecast area could be adversely affected. there would be an immediate and obvious need to strengthen existing structures wherever possible. This would become a priority on the assumption that in most cases people would find it impossible to leave the area for a safer one.

One of the department's activities which would assume greater importance is that of civil defence. In this field, the department's officers and facilities are made available to the overall organisation, and particular assistance is given with communications. Civil defence is aimed at preparing the country for any disaster or emergency, and a major earthquake represents the worst type of disaster. While it is assumed that a disaster could occur at any time, forecasting a particular one would take precedence over ail others, and the orcanisation would have to be amended accordinglv. In the case of a major earthquake being predicted in an urban area, it would have to be conceded that many of the department's operations centres, which are the headquarters of the communications network, are not ideally located. It would be necessary to establish a new system, designed specifically to cope with the situation arising from a major earthquake. As an illustration, while the department's operations centre in Wellington has cuped satisfactorily with emergencies arising from flooding in various parts of New Zealand, it would not be wise to assume that the facility would remain operational if a major earthquake was predicted to occur in the Wellington area. It would be prudent to duplicate the facility elsewhere.

Thus, whereas civil defence is organised to cope with any imaginable emergency, earthquake prediction would require major adjustment to cope with the specific situation. This would certainly be necessary in the case of Ministry of Works and Development in the provision of a nationwide communications network.

On the assumption that there is more than a $50 \%$ probability of the predicted event occurring, the department would be faced with the same questions, of a socioeconomic nature as all other organisations. The solution to relocation of the department's organisation and operations from the area at risk would depend largely on the area itself, and on the precision given to the time scale. In spite of the confidence which should be demonstrated in the design of modern structures, it would be foolhardy for example to continue occupying high rise buildings immediately in advance of the predicted date. The action to be taken would depend largely on the experience gained prior to the predicted earthquake from the performance of structures under earthquakes of similar magnitude.

In New Zealand's case, however, the recent generation of modern structures has not been exposed to damaging earthquakes.
Commonsense alone, and the natural instinct to preserve life and limb, would result in the evacuation of those areas which could suffer as the result of structural collapse. Even if desired, authorities would have extreme difficulty in maintaining the status quo during the specified period of danger. If it is not possible to narrow this period down to a few days, then the social consequences of prediction could be quite ruinous.

In summary, Ministry of Works and Development would first regard the prediction of earthquakes as confirmation of a design philosophy which is achieving general acceptance throughout the country. However, forecasting would need to include a wide range of data to enable the response of structures to the earthquake to be predicted with a similar degree of probability. It is concluded that the knowledge obtained from such predictions could not be withheld from the public, for either moral, professional or feasible reasons. There would be a shift of emphasis in the department's works programme to increase the safety of existing facilities and minimise loss of life and injury. The department's contribution to the civil defence organisation would require reorienting so as to be more effective against the specific emergency. Finally, as with other authorities, the department would have to accept the inevitability of planning all its operations during the earthquake from an area of comparative safety. 